\title{
INFLUENCE OF TIP RELIEF PROFILE MODIFICATION ON INVOLUTE SPUR GEAR STRESS
}

\begin{abstract}
Summary
This paper deals with the effects of linear tip profile modification on the stress of tooth root and tooth flank of involute spur gears. An increase in the tooth flank stress due to the tip profile modification is potentially hazardous because there is an increased risk of micro pitting initiation. The required magnitude of tip relief profile modification depends on the magnitude of tooth elastic deformation that needs to be compensated for. In order to study the effects of linear tip profile modification on gear stress, two matching finite element models of involute spur gear pairs have been created, and tip relief profile modification has been applied to one pair. Tooth root and tooth flank stresses in both gear pairs have been compared in order to establish the effect of tip relief profile modification on gear stress.
\end{abstract}

Key words: $\quad$ involute spur gears, profile modification, tip relief, finite element method, tooth root stress, tooth flank stress

\section{Introduction}

The calculation of gear loading capacity according to ISO $6336[6,9]$ is based on the assumption that gear teeth are absolutely rigid and that the gear tooth profile is ideally accurate. However, the actual gear teeth experience deflection under load. These deflections result in deviations of the relative motion of tooth flanks from the theoretical one and consequently generate transmission errors. Therefore, the tip relief profile modification is implemented to compensate for the deflections of the tooth tip expected under load, which results in reduced transmission errors.

The purpose of tip relief profile modification is to reduce or eliminate the contact shocks during transitions from the double to the single contact of gear teeth and vice versa. Noise is generated during these impacts, and pitch inaccuracies are amplified, resulting in gear tooth deformation. A relief curve is used to modify the involute in the gear tip area in order to reduce the impact influence, particularly in highly loaded gears [15].

\section{Tip relief profile modification}

Tip relief profile modification can be designed in several different ways; however, only linear and parabolic profile modifications are widely applied [8]. Linear profile modifications result in a small transmission error for a known load [13]. On the other hand, the parabolic profile modification results in a smooth tooth flank curve suitable for variable loads, but the transmission error is increased [2]. Therefore, linear tip relief modification in the presence of a known load has been investigated for the purposes of this paper (Figure 1). 


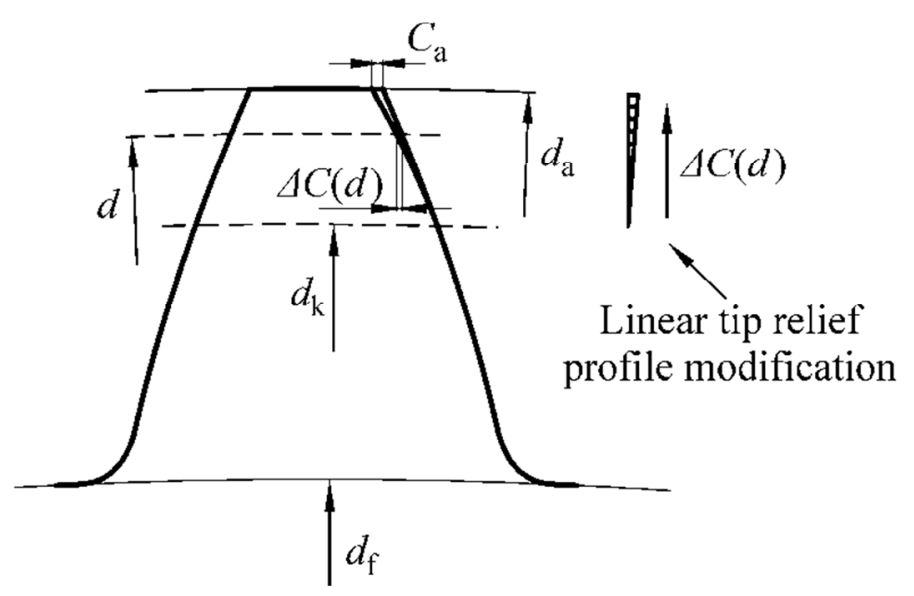

Fig. 1 Linear tip relief profile modification

Tip relief profile modification can be defined as the thickness $\Delta C(d)(1)$ of the material removed along the tooth flank of a particular diameter $d$ with reference to the nominal involute profile.

$$
\Delta C(d)=C_{\mathrm{a}} \frac{d-d_{\mathrm{k}}}{d_{\mathrm{a}}-d_{\mathrm{k}}} .
$$

The tooth tip diameter $d_{\mathrm{a}}$ is defined by gear geometry, while the diameter at the beginning of the profile modification correction $d_{\mathrm{k}}$ has been defined at the meshing point $\mathrm{D}$ of the pinion tooth flank (meshing point B of the wheel tooth flank). The profile relief at the tooth tip $C_{\mathrm{a}}$ must now be calculated.

\section{Calculation of tip relief for nominal load}

The elastic deformation of the gear tooth under nominal load may be regarded as a combination of the deformation of the gear body due to the load distributed on the teeth in mesh and the deformation at the point of contact caused by Hertzian contact stress. Therefore, the tip relief profile modification at the tooth tip $C_{\mathrm{a}}$ is calculated to compensate for the sum of these elastic deformations.

\subsection{Deformation due to Hertzian contact stress}

This deformation is caused by the localized stresses that develop as two curved surfaces undergo local deformation at the point of contact under the imposed load, and depends on the modulus of elasticity $E$ and Poisson's ratio $v$ of the materials in contact. Hertzian theory assumes elliptic stress distribution along the contact area. The width of the deformed area is defined as $2 b_{\mathrm{H}}$ (Figure 2).

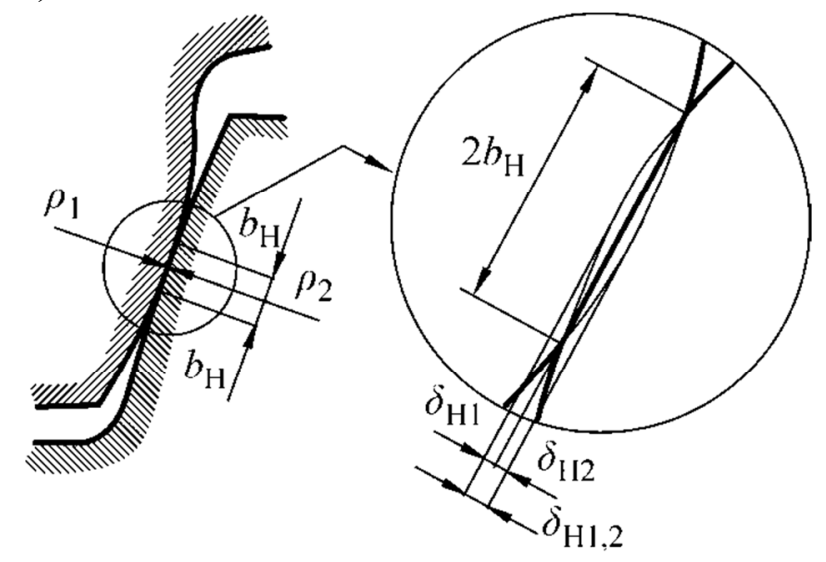

Fig. 2 Deformation due to Hertzian stress (left), enlarged detail (right) 
The maximum deformation is calculated at the centre of the contact area by means of equation (2) [16]:

$$
\delta_{\mathrm{H} 1,2}=\frac{2 F_{\mathrm{bti}}}{\pi b} \frac{\left(1-v^{2}\right)}{E}\left(1.27+0.781 \ln \frac{m_{\mathrm{n}}}{b_{\mathrm{H}}}\right) .
$$

\subsection{Elastic deformation of the spur gear teeth}

The elastic tooth deformation caused by the nominal transverse load in the plane of action $F_{\text {bti }}$ is shown in Figure 3.

The elastic tooth deformation may be calculated by means of expression $(3)[5,15]$ :

$$
\delta_{\mathrm{b} 1,2}=\frac{F_{\mathrm{bti}}}{b} \frac{\left(1-v^{2}\right)}{E}\left(A+B e^{C \cdot \bar{y}_{\mathrm{p}}}+D\right),
$$

where:

$$
\begin{aligned}
& A=-1.05+153 e^{-8.1 x} z^{-(1.75-1.6 x),} \\
& B=0.63+(7.35-0.924 x) z^{-1}, \\
& C=1.28-(2.88+3.68 x) z^{-1}, \\
& D=-1.06+0.638 \ln \left(m_{\mathrm{n}} z\right),
\end{aligned}
$$

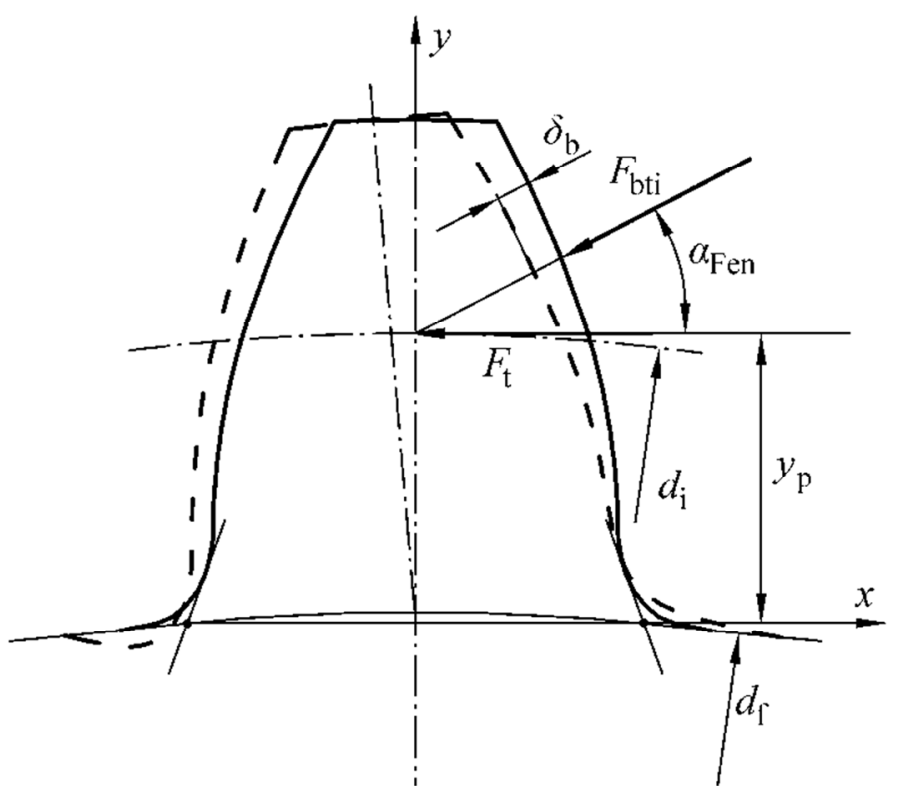

Fig. 3 Elastic tooth deformation

$$
\begin{aligned}
& \bar{y}_{\mathrm{p}}=\frac{y_{\mathrm{p}}}{m_{\mathrm{n}}}=\frac{r_{\mathrm{p}} \cos \left(\alpha_{\mathrm{b}}-\omega_{\mathrm{b}}\right)-r_{\mathrm{f}}}{m_{\mathrm{n}}}, \\
& \alpha_{\mathrm{b}}=\arctan \frac{\rho}{r_{\mathrm{b}}}, \\
& r_{\mathrm{p}}=\arctan \frac{r_{\mathrm{p}}}{\cos \alpha_{\mathrm{b}}},
\end{aligned}
$$




$$
\begin{aligned}
& r_{\mathrm{b}}=\frac{m_{n}}{2}(z+x-2.5), \\
& \omega_{\mathrm{b}}=\frac{\rho}{r_{\mathrm{b}}}-\varphi, \\
& \varphi=\frac{\left(4 x \tan \alpha_{\mathrm{n}}\right)}{2 z}+\operatorname{inv} \alpha_{\mathrm{n}}, \\
& r_{\mathrm{f}}=\frac{m_{\mathrm{n}} z}{2} \cos \alpha_{\mathrm{n}}, \\
& \operatorname{inv} \alpha_{\mathrm{n}}=\tan \alpha_{\mathrm{n}}-\alpha_{\mathrm{n}} .
\end{aligned}
$$

\subsection{Tooth tip relief}

The profile modification must be calculated separately for the pinion and the wheel. The values of the profile relief at the tip of each gear tooth are equal to the total gear deformation; therefore $(16)[5,15,16]$ :

$$
C_{\mathrm{a} 1,2}=\delta_{1,2}=\delta_{\mathrm{b} 1,2}+\frac{1}{2} \delta_{\mathrm{H} 1,2}
$$

\section{Spur gear flank stress}

The flanks of meshing gears are subjected to high contact stresses and to various combinations of rolling and sliding at the point of contact [15]. The fundamental expressions for calculating the Hertzian contact stress of spur gear tooth flanks are given by ISO 6336 [6].

The contact of gear tooth flanks can be approximated to the contact of two parallel cylinders [14], the radii of which are equal to the radii of curvature of the tooth flanks at the point of contact.

The equivalent radius of curvature $\rho_{\mathrm{e}}(17)$ must be calculated in order to calculate the Hertzian contact half width $b_{\mathrm{H}}(18)$ and the Hertzian contact stress $\sigma_{\mathrm{H}}$ at the point of contact (19):

$$
\begin{aligned}
& \rho_{\mathrm{e}}=\frac{\rho_{1} \rho_{2}}{\rho_{1}+\rho_{2}}, \\
& b_{\mathrm{H}}=\sqrt{\frac{2 F_{\mathrm{bti}} \rho_{\mathrm{e}}}{\pi E b}}, \\
& \sigma_{\mathrm{H}}=\sqrt{\frac{F_{\mathrm{bti}} E}{2 \pi \rho_{\mathrm{e}} b}} .
\end{aligned}
$$

Nominal contact stress according to ISO 6336 is calculated using (20) [6]:

$$
\sigma_{\mathrm{H} 0}=Z_{\mathrm{H}} Z_{\mathrm{E}} Z_{\varepsilon} Z_{\beta} \sqrt{\frac{F_{\mathrm{t}}}{b d_{1}} \frac{u+1}{u}} .
$$

The factors $Z_{\varepsilon}$ and $Z_{\beta}$ are equal to 1 for spur gears with transverse contact ratios $\varepsilon_{\alpha}$ which are less than 2 , and are omitted from calculations. 
By expanding the factors $Z_{\mathrm{H}}$ and $Z_{\mathrm{E}}$, and by taking into consideration $F_{\mathrm{t}}=F_{\mathrm{bt}} \cos \alpha_{\mathrm{n}}$, equation (20) may be expanded into (21) as a variation of (19) [17]:

$$
\sigma_{\mathrm{H} 0}=\sqrt{\frac{F_{\mathrm{bt}} E}{2 \pi \rho_{\mathrm{e}} b\left(1-v^{2}\right)}} .
$$

It should be noted that equations (17), (18), (19), and (21) have been developed for the case examined in this paper, in which both the pinion and the gear wheel are made from the same material.

\section{Spur gear root stress}

Gear teeth are subjected to bending, compression and shear stresses during the mesh. One tooth root is subjected to tensile stresses, while the root on the other side of the gear tooth is subjected to compressive stresses. The tooth root subjected to tensile stress is analysed as the tooth breakage is usually initiated under tensile load.

The fundamentals of gear tooth bending stress calculations have been specified by ISO 6336 [6]. This standard assumes that the critical cross-section of the tooth is determined by the tangents on the root fillet profile forming an angle of $30^{\circ}$ with the tooth centreline (Figure 4). The tangents determine the tooth root thickness $s_{\mathrm{F}}$ and the tooth root fillet radius of curvature at the point of tangent intersection $\rho_{\mathrm{F}}$. The nominal transverse load in the plane of action $F_{\mathrm{bt}}$ and its partial component for the current point of contact $F_{\mathrm{bti}}$ can then be used to calculate the bending stress $\sigma_{\mathrm{F}}$.

The tooth root stress of spur gears according to ISO 6336 [6] is calculated using (21):

$$
\sigma_{\mathrm{F} 0}=\frac{F_{\mathrm{t}}}{b m_{\mathrm{n}}} Y_{\mathrm{F}} Y_{\mathrm{S}} Y_{\beta} Y_{\mathrm{B}} Y_{\mathrm{DT}} .
$$

The factors $Y_{\beta}$ and $Y_{\mathrm{DT}}$ are equal to 1 for the spur gears with transverse contact ratios $\varepsilon_{\alpha}$ which are less than 2. Furthermore, the factor $Y_{\mathrm{B}}$ equals 1 as the gears concerned are not thinrimmed.

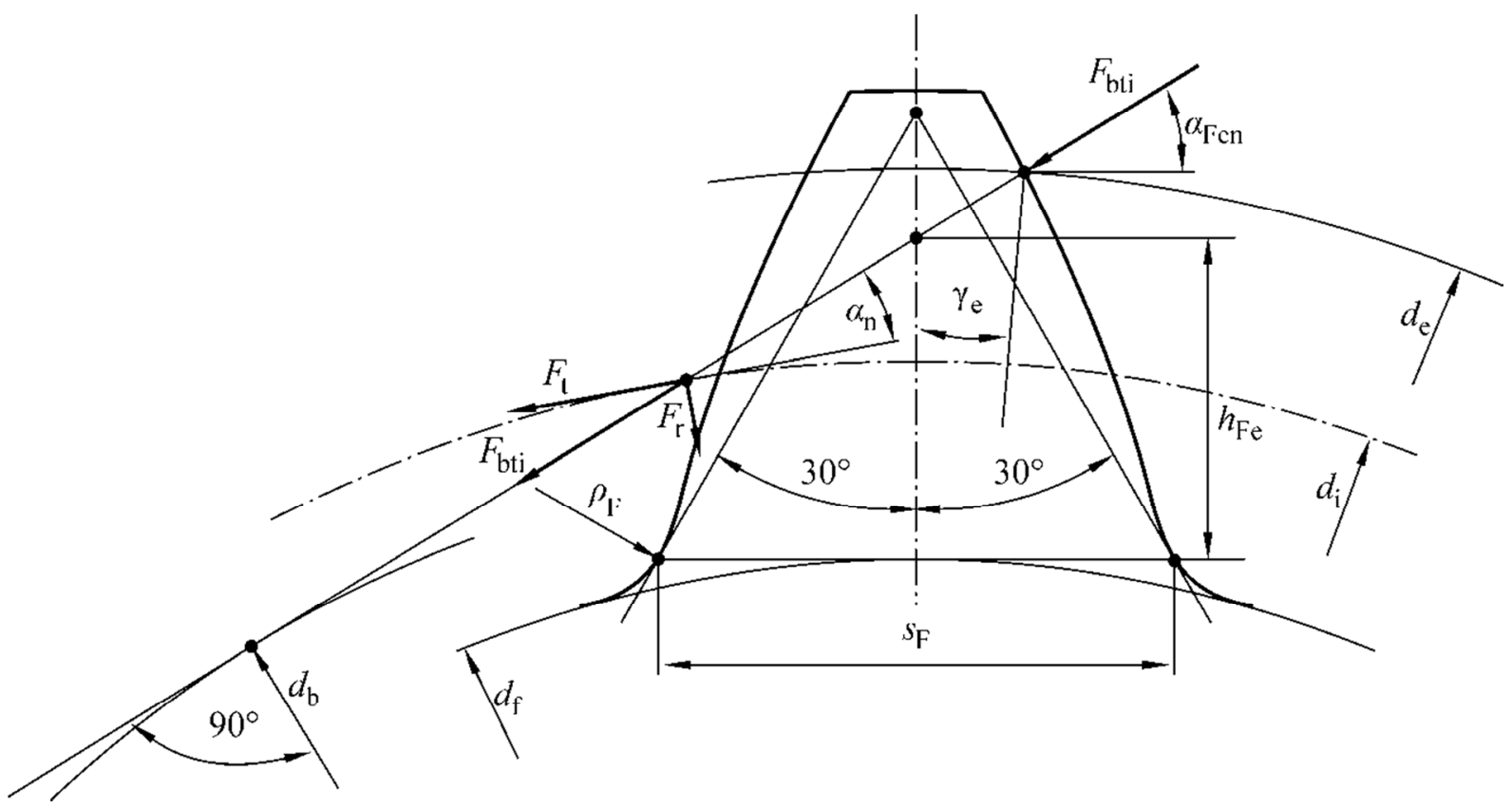

Fig. 4 Calculation of tooth root stress [6] 


\section{Gear pair model data}

A gear pair with the following characteristics has been used in order to perform the finite element analysis (Table 1):

Table 1 Gear pair model data

\begin{tabular}{|l|l|}
\hline Number of teeth & $z_{1,2}=58 / 67$ \\
\hline Profile shift coefficient (pinion/wheel) & $x_{1,2}=0$ \\
\hline Helix angle & $\beta=0^{\circ}$ \\
\hline Normal module & $m_{\mathrm{n}}=12 \mathrm{~mm}$ \\
\hline Normal pressure angle & $\alpha_{\mathrm{n}}=20^{\circ}$ \\
\hline Gear face width & $b_{1,2}=330 \mathrm{~mm}$ \\
\hline Tool addendum factors & $h_{\mathrm{a}}{ }^{*} 01,2=1.25$ \\
\hline Bottom clearance factors & $c_{\mathrm{a} 1,2}{ }^{*}=0.25$ \\
\hline Tool tip radius factors & $\rho_{\mathrm{a}}{ }^{*} 01,2=0.25$ \\
\hline Transverse contact ratio & $\varepsilon_{\alpha}=1.79$ \\
\hline Relief at tooth tip & $C_{\mathrm{a} 1,2}=0.061 \mathrm{~mm}$ \\
\hline Diameter at the beginning of correction & $d_{\mathrm{k} 1,2}=349.223 / 403.358 \mathrm{~mm}$ \\
\hline Modulus of elasticity & $E=210 \mathrm{GPa}$ \\
\hline Poisson's ratio & $v=0.3$ \\
\hline Nominal transverse load in the plane of action & $F_{\mathrm{bt}}=570 \mathrm{kN}$ \\
\hline
\end{tabular}

The tooth tip relief has been calculated in accordance with the theoretical concepts defined in this paper.

\section{Finite element analysis procedure}

The meshing of gears has been simulated using the nonlinear contact analysis performed in ANSYS [1].

The pinion and wheel gears have been modelled as two-tooth gear segments [4], because the other parts of the gear have very little influence on stress values (Figure 5).

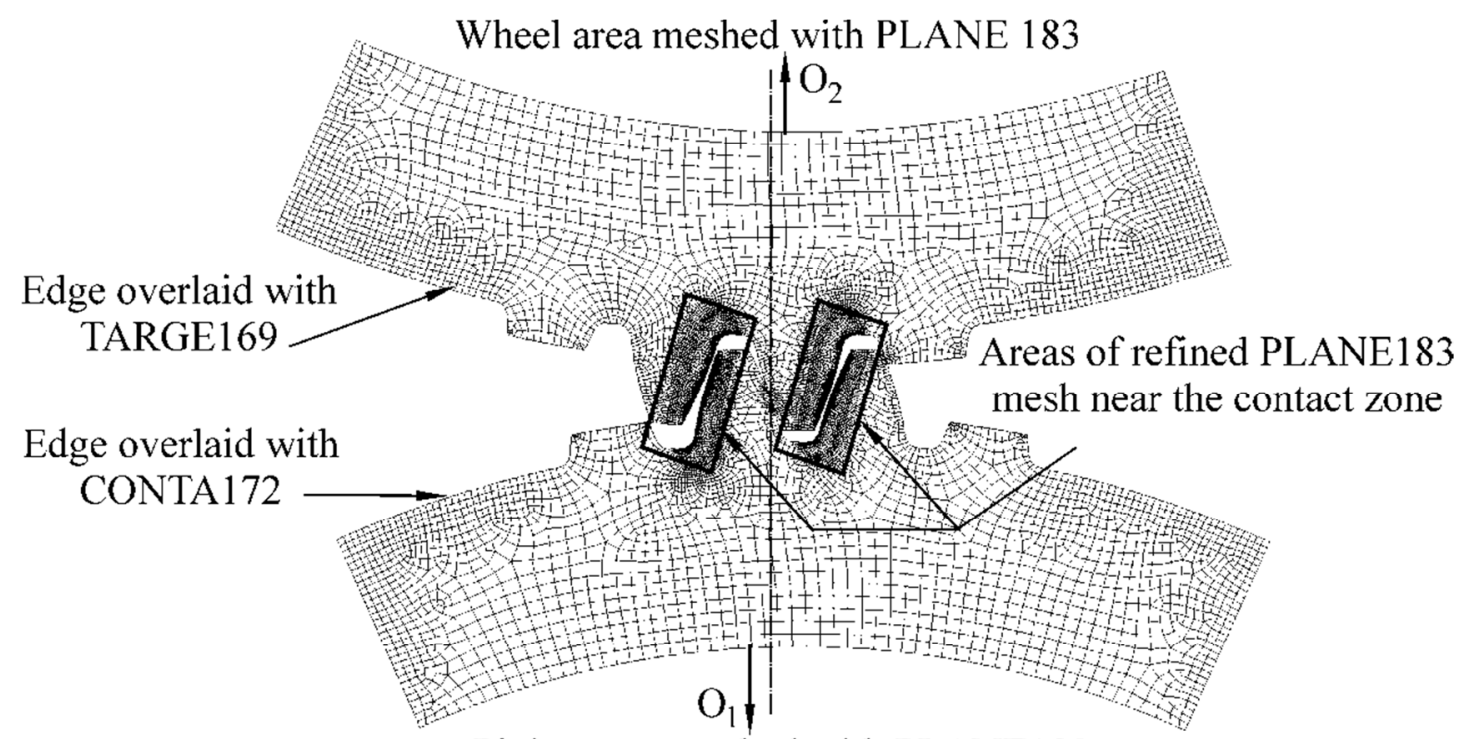

Pinion area meshed with PLANE183

Fig. 5 Finite element simulation setup 
The segment rims have a thickness of $100 \mathrm{~mm}$ below the respective gear tooth root radii in order to avoid the influence of thin rims (rims of less than $5 m_{\mathrm{n}}$ ) on the analysis result [3].

The gear models have been meshed with PLANE183 8-node elements. The finite element mesh was formed using predefined sizes of elements. The PLANE183 mesh was refined near the contact zone in order to improve accuracy [1] as the computer processing power was not an issue in this case $[12,17]$. The outer edge of the pinion model was overlaid with CONTA172 elements, while that of the wheel model was covered with TARGE169 elements.

After the gear models were rotated into their respective positions for the desired points along the path of contact, all degrees of freedom were constrained on the outer side of the wheel model. A cylindrical coordinate system was placed at the centre of the pinion gear model, after which radial movements of the outer side of the pinion gear were constrained. The load was introduced by rotating the pinion model against the wheel model, after which the reaction forces at the point of contact were checked. If the resulting force was within $0.5 \%$ of the nominal transverse load in the plane of action $F_{\mathrm{bt}}$, the load case was deemed acceptable and the results were analysed [17]. It should be noted that the nominal transverse load in the plane of action $F_{\mathrm{bt}}$ is most convenient with finite element analysis as $F_{\mathrm{bt}}$ remains constant at all points along the path of contact and always acts in a direction perpendicular to the gear flank at the current point of contact.

\section{Analysis results}

The gear root stresses along the path of contact have been calculated for both the unmodified model and the model with tooth tip correction, and then compared in order to investigate the influence of profile modification on the gear tooth root and gear tooth flank stresses.

It should also be noted that modified gears come into contact at point $A^{\prime}$ along the path of contact, which is somewhat lower along the tooth flank than point A situated at the wheel tooth tip. A similar change occurs at point E', which is positioned somewhat higher along the wheel tooth flank than point E. Furthermore, the transitions from double to single contact and vice versa occur at points B' (higher than point B) and D' (lower than point D), respectively. This also results in a minor reduction of the transverse contact ratio, paired with an appropriate extension of the area of single contact.

\subsection{Tooth root stress}

The tooth root stress values obtained by finite element analysis are shown for the pinion in Figure 6 and for the wheel in Figure 7.

The tooth root stress of the unmodified pinion rises slowly towards point B along the path of contact, where there is a sharp increase in the tooth root stress due to transition from double to single contact, and then continues to increase towards the maximum at point $\mathrm{D}$ along the path of contact where there is a sudden drop due to the transition back to double contact. These transitions impose additional dynamic loads on the gear tooth root (Figure 6). It should be noted that the gears do not have any initial loads imposed, but the FEM analysis was unable to capture this short period of initial gear loading.

On the other hand, the increase and decrease in the tooth root stress of modified gears are almost linear in the areas of double contact A' - B' and D' - E'. The change in load at the points of transition between the areas of double and single contact ( $\mathrm{B}^{\prime}$ and $\mathrm{D}^{\prime}$ ) is much less pronounced than on unmodified gear pairs with little or no additional dynamic load imposed on the gear tooth root. The maximum tooth root stress value remains at point D', similar to the maximum stress value of unmodified pinions at point $\mathrm{D}$. 
The pinion tooth root stress has been calculated according to ISO 6336 for point D along the path of contact of an unmodified pinion. It has been found that this value matches the pinion tooth root stress at point $\mathrm{D}$ obtained by finite element analysis very well. The maximum tooth root stress of a modified pinion at point $D^{\prime}$ is just slightly higher than the value calculated according to ISO 6336.

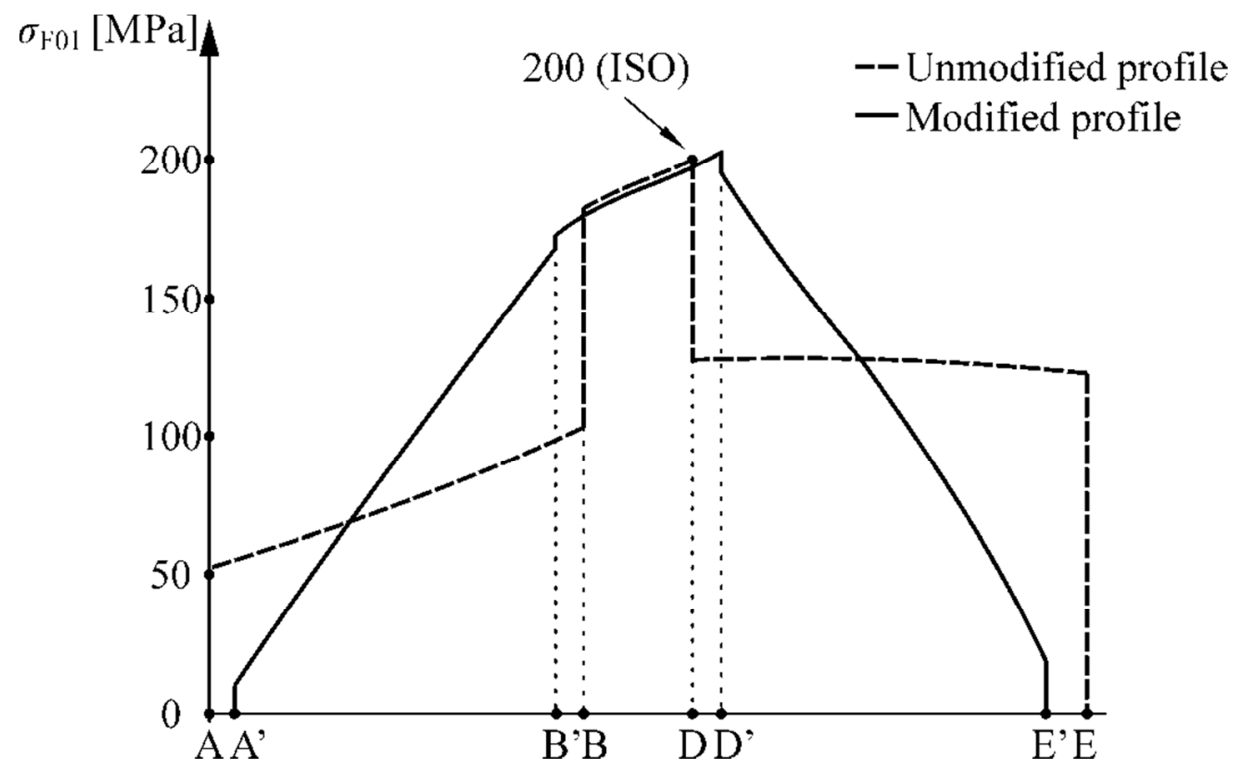

Fig. 6 Tooth root stress of the pinion gear

The tooth root stress of unmodified wheels starts out high due to the long bending arm at point $\mathrm{A}$, and then very slowly increases towards point $\mathrm{B}$ along the path of contact where there is a transition from double to single contact with a sharp rise to the maximum stress value, and then decreases towards point $\mathrm{D}$, at which there is a sharp decrease in the tooth root stress at the transition back to double contact. The tooth root stress then gradually decreases towards point E. These transitions impose additional dynamic loads on the gear tooth root (Figure 7).

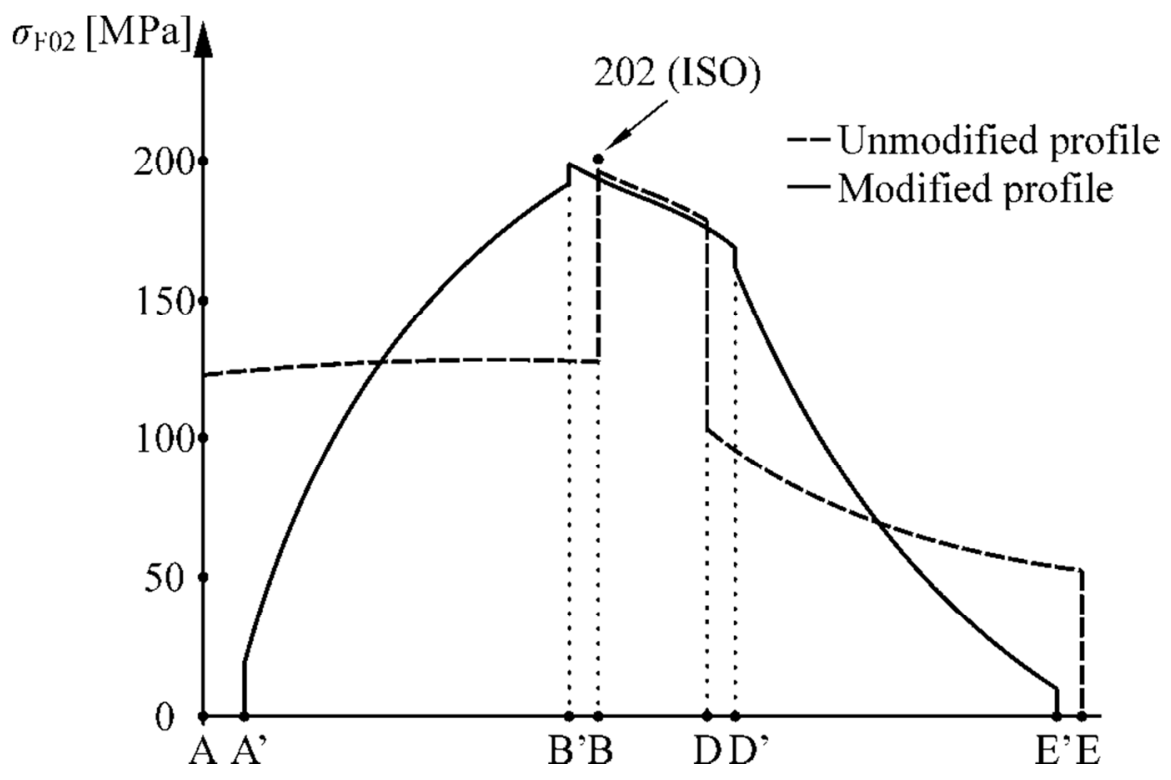

Fig. 7 Tooth root stress of the wheel gear

The tooth root stress increase and decrease of modified gears resemble linearity in the areas of double contact A' - B' and D' - E'. As for the pinion, the change in load at the points of transition between the areas of double and single contact ( $\mathrm{B}^{\prime}$ and $\mathrm{D}^{\prime}$ ) is much less 
pronounced than on unmodified gear pairs, and little or no additional dynamic load is imposed on the gear tooth root. The highest tooth root stress values appear at point B along the path of contact in standard wheels, and at point B' in modified wheels.

The wheel tooth root stress of an unmodified wheel has been calculated according to ISO 6336 for point B along the path of contact. It has been found that this value is slightly higher than the wheel tooth root stress at point D obtained by finite element analysis. The maximum tooth root stress of a modified pinion at point D' is approximately equal to the value calculated according to ISO 6336.

\subsection{Tooth flank stress}

The tooth flank stress values obtained by finite element analysis for the pinion and the wheel are shown in Figure 8.

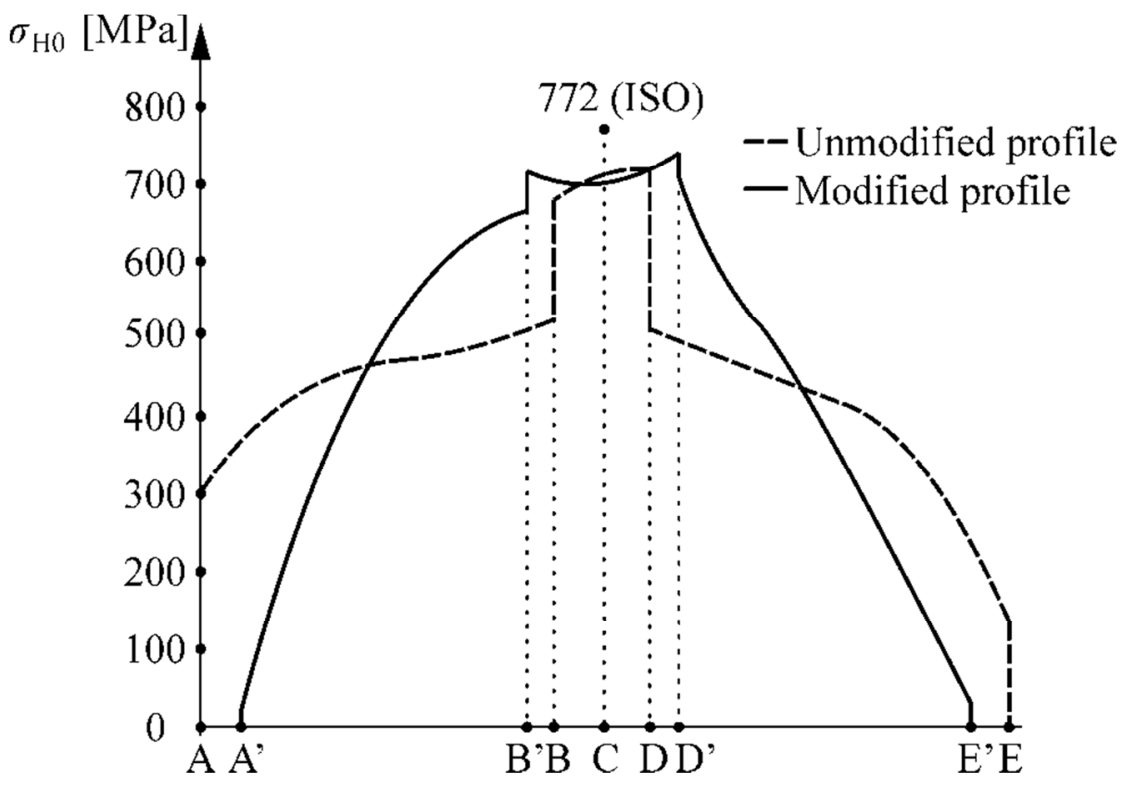

Fig. 8 Gear tooth flank stress

The tooth flank stress of unmodified gears increases towards point B along the path of contact where there is a transition from double to single contact and then decreases from point $\mathrm{D}$ where there is a transition back to double contact. These transitions impose additional dynamic loads on the gear tooth flank (Figure 8). The initial stress spike at point A caused by the contact between the sharp edge of the pinion tooth tip and the flank of the wheel has not been observed as this part of the path of contact is very short. [17].

The tooth flank stress of modified gears gradually increases and decreases in the areas of double contact A' - B' and D' - E', which also means that the initial stress spikes will be avoided with modified gears. The change in load at the points of transition between the areas of double and single contact (B' and D') is much less pronounced than on unmodified gear pairs, and little or no additional dynamic load is imposed on the gear tooth flanks.

The analysis has shown that the highest values of contact stresses appear in the area of single contact B - D for standard gears. The same happens with the modified pair in the area B' - D' with slightly increased stress values in regard to unmodified gears due to smaller tooth flank radii of curvature than those of unmodified gears.

The gear tooth flank stress has been calculated according to ISO 6336 for point $\mathrm{C}$ along the path of contact of an unmodified gear pair. It has been found that this value is slightly higher than the gear tooth flank stress at points D and D' obtained by finite element analysis. 


\section{Conclusion}

The results of the analysis have shown that unmodified gears experience a sudden change in the tooth root and the tooth flank stress at the points of transition between the areas of the single and the double contact of tooth pairs, similar to the theoretical load distribution from [6], and to the results from [11] for unmodified steel gears. The point of highest tooth root stress is point $\mathrm{D}$ for the pinion, and point $\mathrm{B}$ for the wheel gear. The tooth flank stress gradually increases from the contact point A towards the contact point B with an expected increase due to the transition from the double to the single gear tooth contact. The tooth flank stress then gradually declines from the contact point $\mathrm{D}$ towards the contact point $\mathrm{E}$ in the second double contact period. It should also be noted here that the point of highest tooth flank stress could appear at point B for a gear pair of different geometry.

A comparison should also be made with gears to which the tooth tip rounding has been applied, as discussed in [7]. In such gears, only localized reductions in the tooth root and the tooth flank stress will occur, while a reduction in the contact ratio in such cases will be negligible. The overall shape of the tooth root stress diagram will remain similar to the shape of the diagram of unmodified gears, as shown in Figures 6 and 7.

In gears modified with linear profile modification as discussed in this article, both the tooth root and tooth flank stresses increase linearly from the beginning of the mesh at the contact point A' towards the beginning of the single point contact at point B'. The load increase at the transition from double to single contact is much less pronounced than in the case of unmodified gears. The points of highest tooth root stress are point D' for the pinion and point B' for the wheel. Then, the stress gradually decreases as the end of the second double contact at point E' approaches, with only a small shock at the end of the double contact.

The increase in the peak root stress of modified gears appears to be small, as well as the increase in the peak flank stress in the vicinity of contact points B' and D'. As the loads on modified teeth increase gradually in an almost linear fashion, similar to the ideal load increase in the modified gears described in [10], there are no rapid load changes at the transitions from the single to the double contact of tooth pairs, and therefore no significant additional dynamic loads.

It should also be pointed out that the diagram of tooth flank stress shown in Figure 8 has no stress spikes which may be observed near contact points $A$ or $A^{\prime}$ [7]. This is due to the method used in the analysis in which two-dimensional gear models were rotated in predetermined intervals, unlike the dynamic load method used on three-dimensional models, as in [7].

The comparison of tooth root stress values obtained by finite element analysis for modified gears with the values obtained by means of ISO 6336 calculations has shown no significant increase in the peak tooth root and tooth flank stress values.

The disadvantages of the linear tip relief profile modification are the reduction in the transverse contact ratio as points $\mathrm{A}^{\prime}$ and $\mathrm{D}^{\prime}$ are placed further away from the tooth tip in relation to points $A$ and $D$, while points $\mathrm{B}^{\prime}$ and $\mathrm{E}^{\prime}$ are placed closer to the gear tooth tip in relation to points $\mathrm{B}$ and $\mathrm{E}$. This also results in the area of single contact being extended in relation to the area of single contact of unmodified gears. However, the benefits of profile modification appear to outweigh the disadvantages.

Further research should be carried out in order to investigate the effects of profile modification on internal gear pairs as well as the feasibility of profile modification in high contact ratio gears. 


\section{NOMENCLATURE}

$A, B, C, D \quad$ auxiliary factors for calculating tooth deflection, $\mathrm{A}, \mathrm{A}^{\prime}, \mathrm{B}, \mathrm{B}^{\prime}, \mathrm{D}, \mathrm{D}^{\prime}, \mathrm{E}, \mathrm{E}$ ' characteristic points on the path of contact, -

\begin{tabular}{|c|c|c|c|}
\hline$b$ & facewidth, $\mathrm{mm}$ & $Y_{\mathrm{F}}$ & form factor, - \\
\hline$b_{\mathrm{H}}$ & Hertzian contact half width, $\mathrm{mm}$ & $Y_{\mathrm{S}}$ & stress correction factor, - \\
\hline$c_{\mathrm{a}}^{*}$ & bottom clearance factor, - & $Y_{\beta}$ & helix angle factor, - \\
\hline$d$ & $\begin{array}{l}\text { diameter of point with profile } \\
\text { correction, mm }\end{array}$ & $Z_{\mathrm{E}}$ & elasticity factor, - \\
\hline$d_{\mathrm{a}}$ & tip diameter, $\mathrm{mm}$ & $Z_{\mathrm{H}}$ & zone factor, - \\
\hline$d_{\mathrm{e}}$ & $\begin{array}{l}\text { diameter of external point of single } \\
\text { contact, } \mathrm{mm}\end{array}$ & $Z_{\beta}$ & helix angle factor, - \\
\hline$d_{\mathrm{i}}$ & $\begin{array}{l}\text { reference diameter, mm; } d_{1} \text { for } \\
\text { pinion and } d_{2} \text { for wheel }\end{array}$ & $Z_{\varepsilon}$ & contact ratio factor, - \\
\hline$d_{\mathrm{k}}$ & $\begin{array}{l}\text { diameter at the beginning of } \\
\text { correction, } \mathrm{mm}\end{array}$ & $\alpha_{\mathrm{b}}$ & auxiliary angle, $^{\circ}$ \\
\hline$d_{\mathrm{f}}$ & root diameter, $\mathrm{mm}$ & $\alpha_{\mathrm{n}}$ & pressure angle at normal section, ${ }^{\circ}$ \\
\hline$h_{\mathrm{a} 0} *$ & tool addendum factor, - & $\alpha_{\mathrm{t}}$ & pressure angle at pitch circle, ${ }^{\circ}$ \\
\hline$h_{\mathrm{Fe}}$ & $\begin{array}{l}\text { bending arm length (for tooth root } \\
\text { stress calculation), mm }\end{array}$ & $\alpha_{\mathrm{wt}}$ & working transverse pressure angle, ${ }^{\circ}$ \\
\hline$m_{\mathrm{n}}$ & normal module, $\mathrm{mm}$ & $\alpha_{\mathrm{Fen}}$ & load direction angle, ${ }^{\circ}$ \\
\hline$r_{\mathrm{b}}$ & base circle radius, $\mathrm{mm}$ & $\beta$ & helix angle, ${ }^{\circ}$ \\
\hline$r_{\mathrm{f}}$ & root circle radius, $\mathrm{mm}$ & $\gamma_{\mathrm{e}}$ & auxiliary angle, ${ }^{\circ}$ \\
\hline$r_{\mathrm{p}}$ & meshing point radius, $\mathrm{mm}$ & $\delta$ & deformation, $\mathrm{mm}$ \\
\hline$s_{\mathrm{F}}$ & tooth root thickness, $\mathrm{mm}$ & $\delta_{\mathrm{b}}$ & $\begin{array}{l}\text { elastic deformation of the } \\
\text { gear tooth, } \mathrm{mm}\end{array}$ \\
\hline$u$ & gear ratio, - & $\delta_{\mathrm{H}}$ & Hertzian contact deformation, $\mathrm{mm}$ \\
\hline$x$ & addendum modification coefficient, - & $\varepsilon_{\alpha}$ & transverse contact ratio, - \\
\hline$y_{\mathrm{p}}$ & $\begin{array}{l}\text { bending arm length (for elastic } \\
\text { deformation calculation), } \mathrm{mm}\end{array}$ & $\varphi$ & auxiliary angle, rad \\
\hline$z$ & number of teeth, mm & $v$ & Poisson's ratio, - \\
\hline$C_{\mathrm{a}}$ & profile relief at tooth tip, $\mathrm{mm}$ & $\rho$ & $\begin{array}{l}\text { radius of the tooth flank curvature at } \\
\text { the point of contact, } \mathrm{mm}\end{array}$ \\
\hline$E$ & modulus of elasticity, $\mathrm{GPa}$ & $\rho_{\mathrm{a} 0}{ }^{*}$ & tool tip radius factor, - \\
\hline$F_{\mathrm{bt}}$ & $\begin{array}{l}\text { nominal transverse load in the plane } \\
\text { of action, } \mathrm{N}\end{array}$ & $\rho_{\mathrm{e}}$ & equivalent radius of curvature, $\mathrm{mm}$ \\
\hline$F_{\text {bti }}$ & $\begin{array}{l}\text { nominal transverse load in the plane } \\
\text { of action at the current point of } \\
\text { contact, } N\end{array}$ & $\rho_{\mathrm{F}}$ & $\begin{array}{l}\text { tooth root fillet radius of curvature at } \\
\text { the point of tangent intersection, } \mathrm{mm}\end{array}$ \\
\hline$F_{\mathrm{r}}$ & radial force, $\mathrm{N}$ & $\sigma_{\mathrm{F} 0}$ & nominal tooth root stress, $\mathrm{MPa}$ \\
\hline$F_{\mathrm{t}}$ & tangential force, $\mathrm{N}$ & $\sigma_{\mathrm{H}}$ & Hertzian contact stress, MPa \\
\hline $\mathrm{O}$ & gear centre point & $\sigma_{\mathrm{H} 0}$ & nominal tooth flank stress, $\mathrm{MPa}$ \\
\hline$Y_{\mathrm{B}}$ & rim thickness factor, - & $\omega_{\mathrm{b}}$ & auxiliary angle, ${ }^{\circ}$ \\
\hline$Y_{\mathrm{DT}}$ & deep tooth factor, - & $\Delta C$ & thickness of removed material, $\mathrm{mm}$ \\
\hline
\end{tabular}

Indexes: 1 - pinion, 2 - wheel, e - external point of single contact, $\mathrm{i}$ - current point of contact. 


\section{REFERENCES}

[1] ANSYS Mechanical APDL, Software \& Documentation, Ansys Inc. 2014.

[2] Beghini, M.; Bragallini, G. M.; Presicce, F.; Santus, C.: Influence of the linear tip relief modification in spur gears and experimental evidence, Proceedings of the 12th International Conference on Mechanics ICEM 12, Bari, 2004.

[3] Bibel, G.D.; Reddy, S.K.; Savage, M. \& Handsuch, G.F: Effects of rim thickness on spur gear bending stress, NASA Technical Memorandum 104388, Technical Report 91-C-015, Houston, 1991.

[4] Celik, M.: Comparison of three teeth and whole body models in spur gear analysis, Mechanism and Machine Theory 34 (2006), p. 1227-1235. DOI: 10.1016/S0094-114X(98)00058-5

[5] Franulović, M.: Influence of base pitch deviation on stresses in involute gearing, Master's thesis, University or Rijeka, Faculty of Engineering, Rijeka, 2003.

[6] ISO 6336: Calculation of load capacity of spur and helical gears, ISO, Geneva, 2006.

[7] Zhan, J., Fard, M., Jazar, R.: A quasi-static FEM for estimating gear load capacity, Measurement 75 (2015), p. 40-49. DOI: 10.1016/j.measurement.2015.07.036

[8] Litvin, L. F., Fuentes, A.: Gear Geometry and Applied Theory, Cambridge University Press, Cambridge, 2004. DOI: $10.1017 /$ CBO9780511547126

[9] Lovrin, N.; Križan, B.; Vrcan, Ž.: Photoelastic investigation into stresses in high transverse contact ratio gears, Transactions of FAMENA Vol. 33 No. 4 (2009), p. 31-40.

[10] MAAG Gear Book, MAAG Gear Company Ltd., Zürich, 1990.

[11] van Melick, H. G. H.: Tooth-Bending Effects in Plastic Spur Gears, Gear Technology, September/October 2007., p. 58-66.

[12] Marković, K.; Franulović, M.: Contact stresses in gear teeth due to tip relief profile modification, Engineering review: znanstveni časopis za nove tehnologije u strojarstvu, brodogradnji i elektrotehnici Vol. 31 No. 1 (2011), p. 19-26.

[13] Niemann G.; Winter H.: Machinenelemente Band II, Getriebe allgemain, Zahnradgetriebe, Grundlagen, Stirnradgetriebe, Springer-Verlag, Berlin, 1983.

[14] Oberšmit, E.: Ozubljenja i zupčanici, Sveučilišna naklada Liber, Zagreb, 1982.

[15] Obsieger, J.: Some considerations to the choice of profile correction of involute gears, STROJARSTVO, 31 (1989), p. 17-23.

[16] Terauchi, Y., Nagamura, J: On tooth deflection calculation and profile modification of spur gear teeth, International Symposium on Gearing and Power Transmission Proceedings, Vol II, C-27, Tokyo, 1981, p. 159-164.

[17] Vrcan, Ž.: A Contribution to the Research of the Loading Capacity of Internal Involute High Contact Ratio Gears, Doctoral thesis, University or Rijeka, Faculty of Engineering, Rijeka, 2014.

Submitted: $\quad 17.01 .2016$

Accepted: $\quad$ 10.5.2016
Kristina Marković, D. Sc. M. E., Senior Assistant

kristina.markovic@riteh.hr Željko Vrcan, D. Sc. M. E., Senior

Assistant zeljko.vrcan@riteh.hr University of Rijeka Faculty of Engineering Vukovarska 58, HR-51000 Rijeka Croatia 